\title{
ANALISIS METODE DAKWAH DALAM FILM AYAT-AYAT CINTA 2
}

\author{
Abdul Wahab; Nurul 'Ainin Nafi'ah \\ Fakultas Dakwah dan Komunikasi \\ Universitas Islam Nahdlatul Ulama Jepara \\ gusdoel27@unisnu.ac.id.nafiah.nurul17@gmail.com
}

\begin{abstract}
Ayat-Ayat Cinta 2 the movie is a continuation of the previous film, Ayat-Ayat Cinta. This religious genre film is an adaptation of a novel by Habiburrahman El Shirazy with the same title. This research was conducted to examine the Analysis of $\mathrm{Da}^{\prime}$ wah Method conducted by Fahri in Ayat-Ayat Cinta 2 the movie. This study uses a type of qualitative research with Roland Barthes's semiotic analysis method that examines the meaning of denotation, connotation and myth. The data collection technique used is documentation by analyzing scenes and dialogs on film scene footage. From the results of this study, it was found that the method of da'wah in Ayat-Ayat Cinta 2 the movie is the method of bil hikmah, bil mauidzah hasanah, mujadalah and exemplary (demonstration). The dominant method of da' wah is the da' wah method of wisdom and example (demonstration).
\end{abstract}

Keywords : Method of Da'wah, Movie, Roland Barthes's Semiotic

\begin{abstract}
Abstrak
Film Ayat-ayat Cinta 2 merupakan kelanjutan dari film sebelumnya, Ayat-ayat Cinta. Film yang bergenre religi ini merupakan film adaptasi dari novel karya Habiburrahman El Shirazy dengan judul yang sama. Penelitian ini dilakukan untuk menelaah tentang Analisis Metode Dakwah yang dilakukan oleh Fahri dalam Film Ayat-Ayat Cinta 2. Penelitian ini menggunakan jenis penelitian kualitatif dengan metode analisis semiotik Roland Barthes yang mengkaji makna denotasi, konotasi dan mitos. Teknik pengumpulan data yang digunakan yaitu dokumentasi dengan cara menganalisa adegan dan dialog pada cuplikan scene film. Dari hasil penelitian ini, ditemukan bahwa metode dakwah dalam film Ayat-ayat Cinta 2 yaitu metode bil hikmah, bil mauidzah hasanah, mujadalah dan keteladanan (demonstrasion). Adapun metode dakwah yang dominan adalah metode dakwah bil hikmah dan keteladanan (demonstrasion).
\end{abstract}




\section{A. PENDAHULUAN}

Dakwah merupakan usaha yang dilakukan dalam rangka mengajak audiens atau mad'u untuk beriman kepada Allah SWT dan Rasul-Nya. Baik berupa ajakan, perintah maupun larangan. Dakwah bukan hanya memberikan pengertian, mempengaruhi sikap, membina hubungan sosial yang baik, tetapi tujuan yang terpenting dalam dakwah sendiri adalah mengajakmad'u untukmelaksanakanajaranajaran agama dan menjauhi perbuatan yang buruk. Dakwah juga dapat dipahami sebagai proses internalisasi, transformasi, transisi, dan difusi Islam dalam kehidupan masyarakat (Saputra, 2011 : 3).

Tidak semua dakwah akan langsung diterima dengan lapang dada, terlebih ketika kita sebagai seorang dai selaku kaum minoritas di tengah keberagaman. Islam rahmatal lil alamin perlu ditunjukan kepada dunia agar penganut agama lain berpandangan bahwa kehadiran Islam bukanlah sebuah ancaman, tetapi agama pengantar kebahagiaan didunia dan akhirat. Maka perlu menggunakan metode dakwah yang tepat untuk mencapai tujuan dakwah sesuai dengan kondisi sasaran dakwah dan lingkungan yang melingkupinya.

Melakukan aktifitas dakwah dapat menggunakan media apa saja, media dakwah adalah peralatan-peralatan yang dipergunakan untuk menyampaikan materi dakwah kepada penerima dakwah.

Media dakwah yang pada awalnya menggunakan media tradisional, kini berkembang lebih banyak variasinya dengan menggunakan sentuhan-sentuhan teknologi media massa modern baik dengan media cetak seperti buku, majalah, surat kabar, tabloid maupun dengan media elektronik yang kini keberadaannya sudah cukup variatif seperti radio, televisi, film, VCD, internet dan lain sebagainya (Amin, 2009 : 113).

Perkembangan teknologi yang paling besar berkembangnya adalah media audio visual, termasuk salah satunya adalah film. Film terus mengalami perkembangan yang sangat signifikan dan peminatnya juga sangat banyak (Nuruddin, 2014 : 59).

Salah satu film yang memuat dakwah adalah film Ayat-ayat Cinta 2, khususnya tentang metode dakwah yang dapat kita ambil pelajarannya. Film garapan produser Manoj Punjabi dan Sutradara Guntur Soehardjanto ini adalah film kelanjutan dari Ayat-ayat Cinta 1. Kedua film ini merupakan adaptasi dari dua buah novel best seller karya Habiburrahman El Shirazy yaitu novel Ayat-ayat Cinta, dan novel Ayat-ayat Cinta 2 yang berkisah tentang perjalanan cinta Fahri sebagai tokoh utama. Film Ayat-Ayat Cinta 2 telah tayang di tiga negara yaitu Indonesia, Malaysia dan Brunei. Sebulan penayangan di Indonesia, film ini mampu meraih pencapaian besar menduduki tangga ketiga di box office dengan mengumpulkan lebih dari 2,8 juta penonton (Andira Putri, 2018).

Tokoh Fahri menjadi pemeran utama film Ayat-ayat Cinta 2 dengan setting tempat Kota Edinburgh, Skotlandia. Fahri memiliki tetangga beragam agama. Meskipun menemui banyak persoalan, Fahri tetap terus melakukan kebaikan membantu tetangganya. Fahri ingin membuktikan bahwa Islam menolak adanya kedzaliman di 
muka bumi dan mengecam keras tindakan teroris. Bahwa Islam megajarkan manusia untuk saling mengenal, saling mencintai dan saling menghormati.

Fahri memilih tetap tinggal di sebuah perumahan yang multikultural untuk mengobati kerinduannya kepada kampung halamannya Indonesia. Di Indonesia memiliki ideologi yang tidak dimiliki negara lain yaitu Pancasila yang menjamin adanya keberagaman. Menurut Fahri meskipun berada di luar negeri Pancasila harus tetap hidup karena tidak terikat geografi, tetapi melekat di hati. Sebagaimana semboyan Bhinneka Tunggal Ika yang harus diamalkan di mana pun kita berada.

Dalam film ayat-ayat cinta 2, selain bergenre romantis yang sarat akan nilai poligami juga memunculkan tokoh Fahri yang menunjukan perilaku mencerminkan metode dakwah diterapkan sesuai permasalahan dan karakteristik sosial masyarakat. Selain dengan kebaikan dan keteladanannya dalam membantu tetangga, Fahri juga pada akhirnya menerima ajakan Baruch berdebat ilmiah di Universitas Edinburgh tempat di mana Fahri menjadi dosen.

Dari beberapa penggalan film di atas, peneliti tertarik untuk melakukan sebuah penelitian guna mengetahui metode dakwah yang dianalisis dalam film Ayatayat Cinta 2.

\section{B. METODE PENELITIAN}

Penelitian ini menggunakan jenis penelitian kualitatif. Penelitian kualitatif menurut Denzin dan Lincoln adalah penelitian yang menggunakan latar alamiah, dengan maksud menafsirkan fenomena yang terjadi dan dilakukan dengan jalan melibatkan berbagai metode yang ada (Djam'an, 2009:24).

Metode yang dipakai adalah analisis Semiotika Roland Barthes. Analisis semiotik merupakan cara atau metode untuk menganalisis dan memberikan maknamakna terhadap lambang-lambang yang terdapat suatu paket lambang-lambang pesan atau teks (Pawito, 2007:155)

Teks dalam semiotik adalah segala bentuk serta sistem lambang (signs) baik yang terdapat pada media massa seperti tayangan televisi, karikatur, film, siaran radio, dan iklan maupun yang terdapat di luar media massa seperti lukisan, patung, candi, monumen, fashion show dan menu masakan dalam food festival (Pawito, 2007:156).

Roland Barthes membagi 3 kajian dalam penelitian semiotika, yang dalam hal ini berlaku pada film yakni, denotasi, konotasi dan mitos atau ideologi. Lewat analisis ini, primary sign adalah denotative sedangkan secondary sign adalah satu dari connotative semiotics. Maka jika ditarik garis besarnya dalam model ini Fiske menyebutnya sebagai Signifikasi dua tahap (two order of signification). Dalam signifikasi tahap pertama ini merupakan hubungan antara signifer (ekspresi) dan signified (content) di dalam sebuah tanda terhadap sebuah realitas external. Itu yang disebut Barthes sebagai denotasi yaitu makna paling nyata dari tanda (sign).

Menurut Barthes, denotasi merupakan sistem signifikasi tingkat pertama yaitu apa 
yang digambarkan tanda terhadap sebuah obyek. Denotasi diperoleh dari pengamatan langsung dari tanda-tanda yang ada yang menghasilkan makna nyata, atau makna yang sebenarnya hadir.

Sedangkan konotasi merupakan signifikasi tingkat kedua. Konotasi merupakan penciptaan makna lapis kedua yang terbentuk ketika lambang denotasi dikaitkan dengan aspek psikologis, seperti perasaan, emosi, atau keyakinan. Karena pada dasarnya penanda konotasi dibangun dari tanda-tanda sistem denotasi. Dalam hal ini, bahwa denotasi lebih menitik beratkan pada ketertutupan makna (Fiske, 1990:122).

Mitos adalah sebuah nilai yang ada di dalam masyarakat. Pada hakikatnya usaha manusia rasional adalah mitos, sebab usaha manusia rasional tidak dapat berdiri sendiri, tidak otonom, tidak dapat mengenal dirinya sendiri. Usaha manusia rasional itu terjadi, ada dan mengenal dirinya hanya berkat dan di dalam mitos. Dengan kata lain, usaha manusia rasional itu niscaya atau tidak dapat tidak adalah mitos sendiri (Alex, 2013:223).

\section{HASIL DAN PEMBAHASAN}

Tanpa mengurangi dari esensi cerita keseluruhan, peneliti mengidentifikasi 6 scene yang berkaitan dengan rumusan masalah yang diteliti. Tidak semua scene dalam film diteliti, agar analisis data yang ada sesuai dengan fokus penelitian yaitu metode dakwah dalam Fim Ayat-ayat Cinta 2 serta dakwah paling dominan yang dilakukan oleh Fahri.

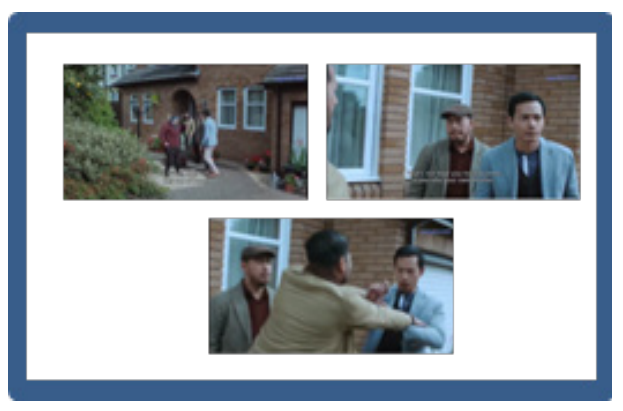

Gambar 1. Scene 1 Depan Rumah Nenek Catarina

Metode dakwah yang dilakukan Fahri dalam dialog dan potongan adegan di sence ini adalah sikap Fahri yang memilih diam dan mencegah Hulusi membalas perbuatan Baruch. Ini menunjukan bahwa Fahri menjalankan metode dakwah Bil Hikmah melalui sikap bijaksana Fahri yang tetap sabar dan tidak membalas keburukan dengan keburukan pula.

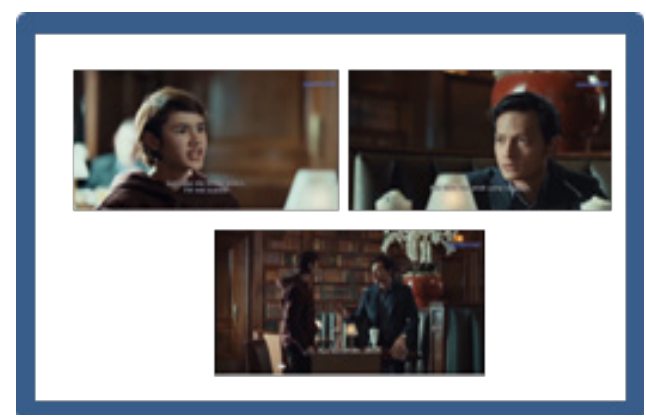

Gambar 2. Scene 2 di Restauran

Metode dakwah yang dilakukan Fahri ditunjukkan melalui dialog dan potongan adegan "Lets be Friend, Jason. Please.. Duduk, please. Setelah ini kalau kamu butuh sesuatu, apapun. Selama masih ada di mini market saya, bisa kamu ambil. Gratis". Ini menunjukan bahwa metode dakwah bil hikmah yang dilakukan Fahri dengan tetap bersikap lapang dada berbuat baik meskipun seseorang tersebut telah melakukan kejahatan. 


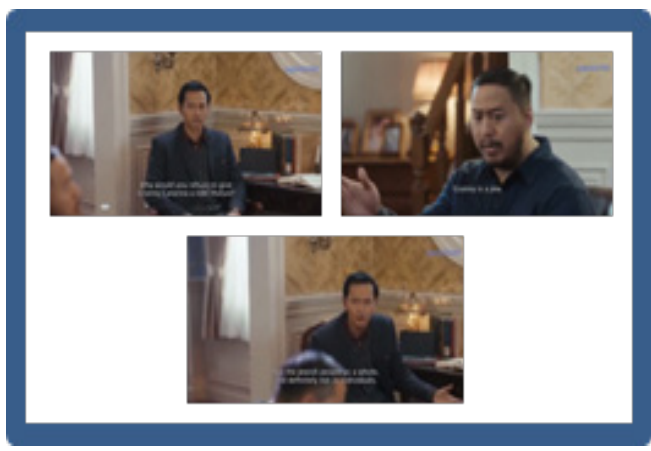

Gambar 3. Scene 3 di Ruang Keluarga Rumah Fahri

Metode dakwah yang dilakukan Fahri ditunjukkan melalui dialog "Nenek Catarina itu tetangga kita. Kita harus membantunya. Membantu tetangga itu ajaran Rasulullah. Apa kamu yanglupa? Yangkitatentangituzionisnya, kedzalimannya. Bukan kaum Yahudinya apalagi orang perorangnya". Metode yang dilakukan Fahri ini adalah mauidoh hasanah dengan memberikan nasehat dan pengajaran bahwa kita harus tetap berbuat baik kepada siapapun tanpa mempedulikan asal-usul, status sosial, agama, maupun jenis kelamin.

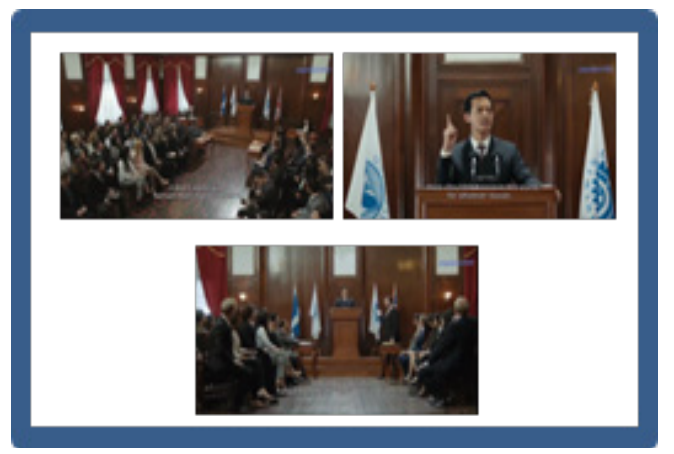

Gambar 4. Scene 4 Auditorium Universitas Edinburgh.

Perilaku Fahri dalam scene tersebut mencerminkan metode dakwah mujadalah yaitu dakwah yang dilakukan melalui jalan diskusi atau berdebat dengan cara yang terbaik dan menghindari adanya debat kusir.

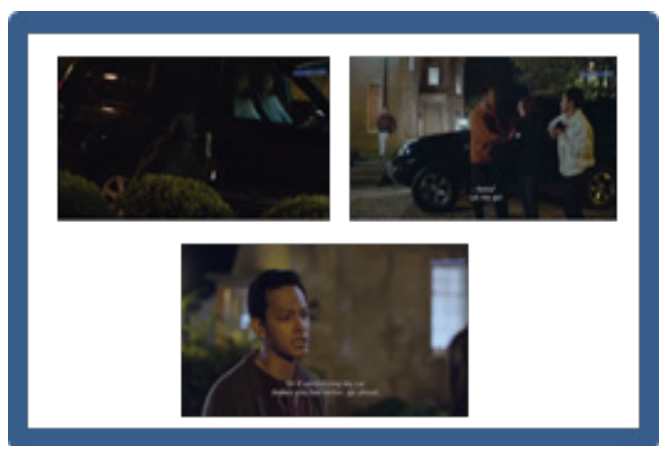

Gambar 5. Scene 5 Depan rumah Fahri

Dapat kita lihat scene di atas bahwa Fahri menunjukan bagaimana tetap berakhlak baik meskipun Keira berulang kali meneror Fahri dengan mencoretcoret mobilnya. Fahri meminta Hulusi dan Misbah untuk melepaskan Keira dan tidak melaporkan ke Polisi sejak tahu bahwa Keira lah pelaku terornya selama ini walaupun kedua sahabatnya tersebut telah membujuknya. Mengetahui hal tersebut, Keira bukannya meminta maaf justru malah menantangnya.

Apa yang dilakukan Fahri tersebut merupakan cerminan dakwah melalui keteladanan (demonstration). Bahwa dakwah akan lebih efektif dilakukan seseorang dengan menunjukkan akhlak dan perbuatan Islamiyah daripada melalui tutur kata dan retorika. Sikap keteladanan yang ditunjukan Fahri adalah ketika Ia mampu bersabar terhadap gangguan yang ditimpakan kepadanya serta memaafkan kesalahan orang tersebut padahal Ia mampu untuk membalasnya. 


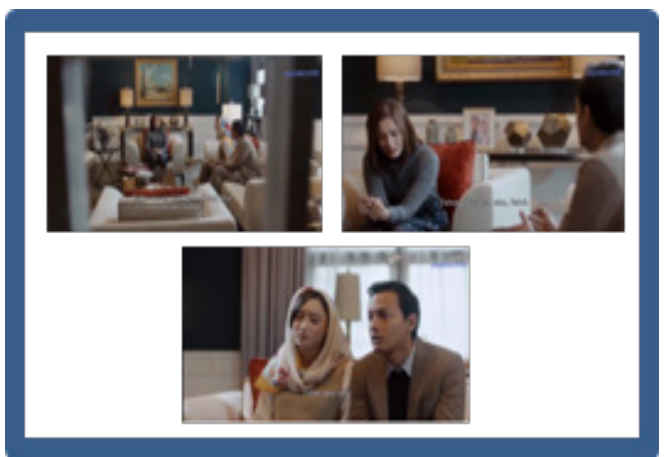

Gambar 6. Scene 6 Ruang Tamu

Hasil analisis di atas dapat ditarik kesimpulan bahwa metode dakwah yang dilakukan Fahri dalam scene 6 adalah dakwah Keteladanan (Demonstration). Dakwah dengan metode keteladanan ini ditunjukan Fahri dengan menyembunyikan kebaikannya menolong Keira dengan mengirimkan seorang guru les biola. Padahal selama ini Keira dan keluarganya selalu memusuhi dan meneror Fahri atas dendam meninggal ayahnya akibat bom London.

\section{KESIMPULAN}

Metode dakwah yang terdapat dalam film Ayat-Ayat Cinta 2 sebagaimana yang dilakukan oleh Fahri adalah metode dakwah bil hikmah dengan sikap kebijaksanaan, bil mauidzah hasanah dengan memberikan nasehat dan pengajaran, bil mujadalah dengan berdebat, serta keteladanan (demontrasion) dengan menunjukkan akhlak dan perbuatan yang mencerminkan kehidupan yang islamiyah.

\section{IMPLIKASI DAN KETERBATASAN PENELITIAN}

Untuk peneliti selanjutnya, dapat mengembangkan penelitian yang tidak hanya berasal dari sudut pandang Fahri sebagai tokoh utama. Karena kebanyakan penelitian yang peneliti temui sebelumnya hanya meneliti tokoh Fahri, sebaiknya dapat meneliti dari sudut pandang tokohtokoh lain. 


\section{DAFTAR PUSTAKA}

Alex, Sobur. (2013). Filsafat Komunikasi. Bandung: PT Remaja Rosdakarya.

Amin, Samsul Munir. (2009). Ilmu Dakwah. Jakarta: Amzah.

Anas, Ahmad. (2006). Paradigma Dakwah Kontemporer: Aplikasi Teoritis dan Praktis Dakwah Sebagai Solusi Problematika Kekinian. Semarang: Pustaka Rizki Putra.

Fiske, John. (1990). Cultural and Communication Studies: Sebuah Pengantar Paling Komprehensif. Yogyakarta: Jalasutra.

Nuruddin. (2014). Pengantar Komunikasi Massa. Jakarta: PT Rajagrafindo Persada.

Pawito Ph.D. (2007). Penelitian Komunikasi Kualitatif. Yogyakarta: LKiS Pelangi Aksara.

Saputra, Wahidin. (2011). Pengantar Ilmu Dakwah. Jakarta: PT Rajagrafindo Persada

Satori, Djam'an, Aan Komariah. (2009). Metodologi Peneliian Kualitatif. Bandung : ALFABETA

Putri, Andira. (2018). Ayat-Ayat Cinta 2 Tayang Terakhir Kali, Berikut Total Jumlah Penontonnya. Available at: https:/ / www.tabloidbintang.com/ film-tv-musik/kabar/read/90761/ ayatayat-cinta-2-tayang-terakhirkali - berikut - to tal-jum la hpenontonnya. Diunduh pada tanggal 3 Desember 2019. 